\title{
Distant Teaching: A Way to Face COVID-19 Pandemic in a Public University
}

\author{
Ana María Paredes Arriaga \\ Universidad Autónoma Metropolitana \\ Luis Fernando Muñoz González \\ Universidad Autónoma Metropolitana \\ María Cristina Alicia Velázquez Palmer \\ Universidad Autónoma Metropolitana
}

\section{Abstract}

In México, first COVID-19 patient was identified in February and from March 23 on confinement measures were taken by the government, including the suspension of activities at universities. This paper objective is to explore the challenges that professors of a public university faced while moving into a distant teaching practice in the pandemic context. Universidad Autónoma Metropolitana is located in México City and up to the pandemic, most of its faculty lacked experience with online education, so the Emerging Distant Education Project was implemented. A qualitative design was developed and in-depth interviews were made to gather information from members of the Business Administration Faculty. Main findings show that in a short time, professors managed to redesign the courses and to develop materials, while trainning themselves in the use of educational platforms, videoconference and communication devices. Among positive experiences they mentioned widening their teaching skills, the positive and helpful attitudes from students, technical support from the institution and the achievement of learning objectives; while on the negative side they mentioned that math contents demanded an extra effort in order to secure students comprehension. Technical problems with the internet and the lack of a proper learning environment were cited as barriers to students' optimal academic achievement. Most of professors defined their experience as "a challenge". In conclusion, professors took on and overcame the challenges in order to continue classes and to achieve the academic objectives of the term.

Keywords: distant education, COVID-19, public university, higher education, pandemic 


\section{Introduction}

More than six months after the World Health Organization (WHO) declared the "coronavirus" (COVID-19) a pandemic, it continues to spread throughout the world. As of October 7, there were 36 million confirmed cases in 193 countries and more than one million deaths (rtve.es, 2020). In many countries, including those with apparent success in controlling the disease, infections continue to increase (BBC, 2020).

The pandemic arrives in México on February 28 when the first patient is identified in México City (CDMX), and the second in the state of Sinaloa (Gobierno de México, 2020). From that moment on, the Undersecretary of Prevention and Health Promotion, Hugo López-Gatell R., urges the population to take safety measures such as: use of antibacterial gel, frequent hand washing, avoid physical contact with other people, drink purified water, do not share food, use sanitizers at all times, among other preventions. However, the country continues with its daily life, and it is until March 16 when the Ministry of Health (SS) announces the implementation of the "National Healthy Distant Journey" as another preventive measure. Thus, as of March 23, non-essential activities are suspended, mass concentration events are rescheduled, academic activities are suspended at all educational levels; those measures would conclude on April 19, and lasted until May 30; starting on June 1, the "new normal", according to which activities would gradually be renewed; as a matter of fact, contagions continue in almost the entire country at the beginning of October (Gobierno de México, 2020). Despite the measures taken by the government, as of October 7, in México a total of 794, 608 cases and 82,348 deaths were reported (Navarro, 2020).

In the field of higher education, this emergency caused the massive closure of activities, having to take Higher Education Institutions (HEIs) a series of measures to comply with government instructions; Therefore, in an abrupt and obligatory way, face-to-face academic activities were suspended, giving rise to distant education, trying to provide teachers and students with the information technology and infrastructure that would allow them to continue with their academic activities (Sánchez, M., et. , al.).

The transition from face-to-face and school-based education to non-face-to-face modalities, made both teachers and students leave traditional classrooms, to necessarily become users of technological tools to interact remotely with each other, highlighting the needs of infrastructure that HEIs have, (Sánchez, M., et., al.); as well as the shortcomings on the part of teachers and students.

In this context, the present study had the general objective of exploring the challenges faced by the professors of a public university when transitioning from face-to-face education to the distant modality, in the context of the COVID-19 pandemic in México. 


\section{Distant education}

Undoubtedly, distant education has meant a solution to the growing demand at different educational levels, as well as to the displacement needs of a large number of people, resulting in greater autonomy in students, since there is a less dependence on the teacher, in general terms. This was already seen as a trend prior to the current COVID-19 pandemic.

In general, it is stated that distant education should represent an ideal complement to face-to-face teaching. In this sense, the available technology should be used in a rational way, with the expectation of being able to increase efficiency and effectiveness in terms of coverage, as well as the attendant costs.

According with the above, it is necessary to highlight the relevance of distant education, as an instrument that enhances the propagation of knowledge. This is particularly important in societies where the demand for education and training is increasing.

In that order of ideas, more than as mutually exclusive options, traditional and distant education must harmonize their respective challenges, in a dialectical process where educational institutions adapt their methods according to existing and available technologies, and in turn these respond to those dynamics. (Alfonso, 2003)

Padula (2003, p. 1) defines distant education as:

“... A non-face-to-face educational methodology, based on multi-directional mediated communication (which implies wide possibilities of participation of dispersed students, with a high degree of autonomy of time, space and commitment), on the teacher's orientation (given in the design), on the choice of the appropriate means for each case considering the subjects and the possibilities of access of the recipients, and on the tutorials".

Its flexibility stands out as a very favorable characteristic of distant education, which allows many people to access the courses, without having as a restriction the time or space to do so (Padula, 2003).

A problem within distant education is its comparison with traditional education and with those who are in charge of a process in this area. On one hand, there is the position of those who affirm that only the face-to-face is of quality, treating it as a matter of mutually exclusive alternatives, and on the other, those who consider that the first can give a necessary plus to the second (Sangrà, 2002).

Among the relevant aspects to consider in distant education are the means used, "namely: Direct human contact (face to face). Texts (even fixed graphics). Audio. Television. Computing". (Bates, 1999, p. 34). As well as, the development of the instructional design, which is not always given due attention, the evaluation processes and the cost of communication, which in the case of face-to-face education is not a variable to be considered (Dorrego, 2016). 
Distant education represents an option that is gaining more importance every day given the need of many countries to expand enrollment at different educational levels, and the central role that education plays in the social and economic development of countries (Aparici, 2002).

On the other hand, the Covid-19 pandemic has put educational systems to the test around the world, and has accelerated the digitization of teaching-learning processes and promoted distant education, and its use will most likely increase in the future.

\section{Institution under study}

The present study was carried out at the Universidad Autónoma MetropolitanaUnidad Xochimilco (UAM-X), which is a public university located south of México City (CDMX). 18 undergraduate and 32 postgraduate degrees are taught there. This unit is characterized by its educational model called modular system, in which each module is made up of four components, Theory, Research, Workshop and Mathematics. The teaching-learning process of the module as a whole revolves around a research question that corresponds to a problem of reality, which the student will face in their professional practice.

In order to give continuity to academic activities, the UAM put into practice the Emerging Remote Teaching Project (PEER in Spanish), starting in May of this year, whose central strategy is to teach courses mediated by technologies, and with full curricular validity (PEER, 2020). Likewise, to support students who did not have computer equipment and / or internet connection, scholarships were awarded in kind (tablets and SIM cards); while the teachers attended virtual courses on educational platforms, technological resources used for teaching work; and they were provided with Zoom licenses.

\section{Methodology}

The confinement derived from the Covid-19 pandemic made it necessary for Higher Education Institutions (HEIs) to develop strategies to continue their academic activities in a distant mode. As mentioned, in the case of UAM-X, the PEER was implemented, based on which the following objective was formulated:

Know the challenges faced by the professors of a public university when moving from a face-to-face teaching-learning process to a remote teaching process in the context of the Covid-19 pandemic.

To this end, a case study was carried out using an exploratory qualitative design. The information was collected through in-depth interviews with six professors of the Bachelor's degree in Administration from the trimesters of the Basic Professional Core (4 to 12). The interview guide included the following dimensions:

Previous experience with online courses

Didactic strategies used and coverage of learning objectives 
Positive and negative aspects of having taught the course remotely

Modification of the way of approaching the module based on their experience with remote teaching

Evaluation of the experience of having completed the term remotely

Suggestions to improve remote education in the institution

\section{Analysis of results}

The analysis of the results was carried out based on the dimensions of the topic guide, identifying the most significant testimony phrases of the professors. ${ }^{1}$

Half of the interviewees indicated having previous experience in distant education, mainly in training courses, or of short duration; and the most experienced, in fact, started his teaching career at a virtual university. This situation shows us the diversity and the level of previous experience existing among the professors at the time of implementing remote teaching.

For the development of the courses, the teachers made use of different didactic strategies that included virtual classrooms, means of communication such as mail, chat; as well as different ways to promote interaction with and between students, such as forums and videoconferences through Zoom. Although some teachers indicate that they tried to make their class as close to the classroom as possible, there was a trend towards an asynchronous mode. Likewise, the teachers emphasized the need to develop materials, to provide students with access to various ways of acquiring and reinforcing knowledge and skills, which required them to dedicate additional time to these activities, which on the other hand, also strengthened and expanded his didactic strategies, as can be seen in the testimony sentences (Table 1).

Table 1 Testimony phrases Teaching strategies

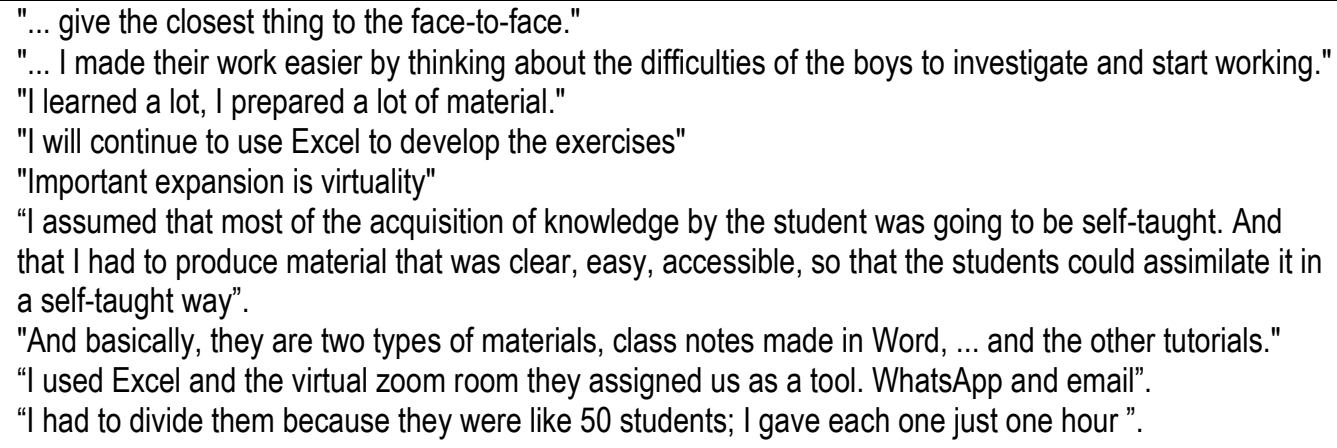

Source: self-made

\footnotetext{
1 The analysis was carried out by referring to the components of the modules, which as mentioned are four: theory, research, workshop and mathematics.
} 
A strategy that they also used was to divide the students into small groups, as well as to reduce class hours, which in some cases were four, to facilitate interaction and understanding of the topics.

Regarding the coverage of the learning objectives, the respondents indicated that these were generally covered; however, depending on the content, in some cases they had to modify the program and focus on the central themes. For some mathematics content, the fact that the students had a computer at hand facilitated the resolution of exercises and this resulted in a decrease in the time required for learning. Another point that contributed to understanding the topics was the development of tutorials, so that students could watch the video over and over again and study at their own pace.

Regarding the research component of the module, each quarter the students go to an organization in which they develop their research work, which in this ocassion was not possible. However, the professors point out that they looked for alternatives, such as studying widely known companies, or questions that could be solved by collecting information on the Internet. In other cases, they tried to advise companies owned by people close to the students. In the opinion of the respondents, the investigations were very interesting and the learning objectives were achieved. On the other hand, professors mention that the role of the student became more active and this is something that should be promoted when returning to the classroom (Table 2).

Table 2 Testimony phrases Coverage of learning objectives

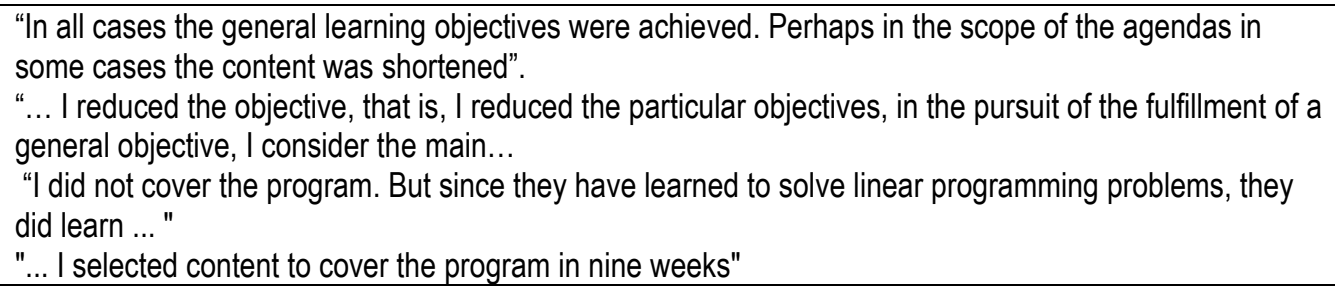

Source: self made

Among the aspects that negatively affected academic activities are technical failures in relation to the internet connection, mainly in the case of students; as well as the lack of an adequate teaching-learning environment. For some students it was difficult to have a quiet place and they also had to share equipment and connection with their relatives. Likewise, the aspect of socialization, of coexistence with their companions was lost; and for teachers remote education represented a greater workload.

As positive aspects of remote teaching, the teachers coincide in that the most important thing is that the activities were continued and the students did not see their studies interrupted, and in the case of those who were studying the last trimester, they were able to complete it. Likewise, the fundamental aspects of the modular system were strengthened as the level of responsibility and autonomy of the students 
increased; and in the case of teachers, their role also changed. To the above, it is added that it was possible to avoid infections (Table 3 ).

\section{Table 3. Positive and negative aspects of remote teaching}

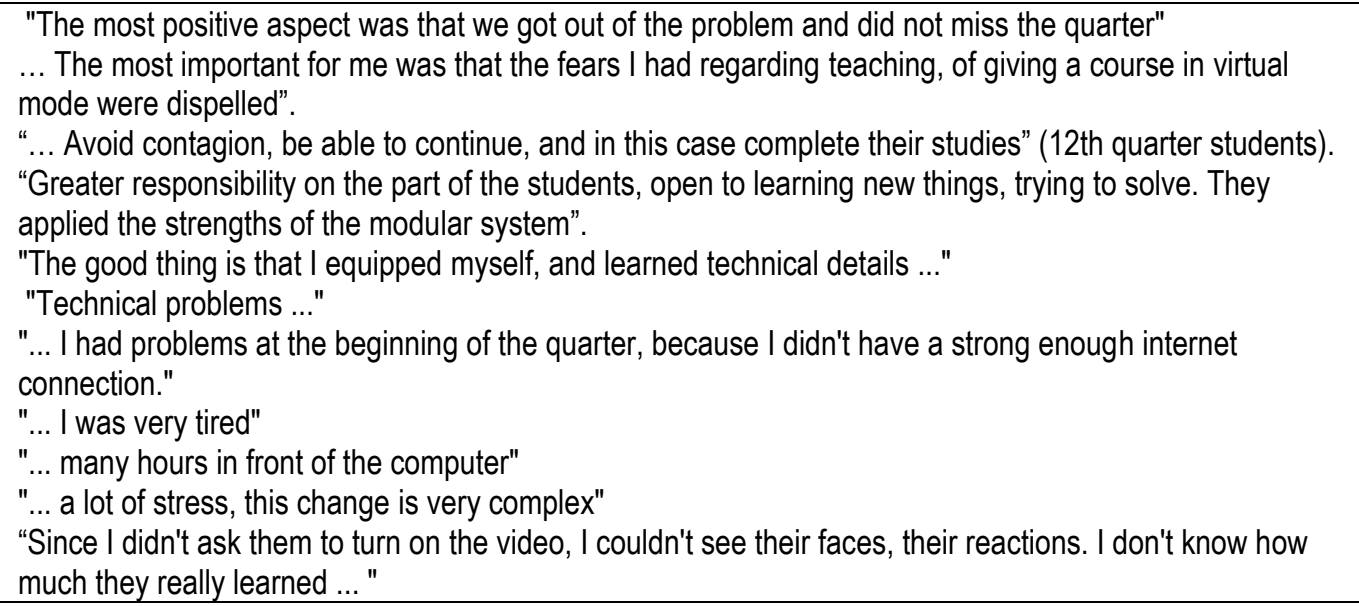

Source: self made

In general terms, the teachers consider that taking the courses remotely does not significantly affect the acquisition of knowledge by the students, but it does affect a comprehensive training, by losing contact on a personal level and the possibility to participate and develop oral expression skills.

Table 4 Effects of remote education on the training of students

"... Neither remotely, nor in person, let's say learning is optimal. We are not able to make the most of the talent and capacity of the students".

"... Student participation, oral expression can be affected".

"I don't think it affects their learning; it is not the course that decides whether the student is good or bad, they are immersed in a dynamic and when something like this happens they do not like change".

Source: self made

The professors also indicated that upon returning to face-to-face classes they would continue to use some of the remote education learning strategies, such as the virtual classroom, tutorials, prior sending of materials, participation in forums, among others; since they consider that face-to-face and distant education complement each other. Similarly, one of the interviewees pointed out that from now on, education should be hybrid, since it is not necessary for students to stay at the university for so long, and this would also contribute to increasing enrollment. However, there is a preference for teaching classes in person.

When the interviewees were asked to rate their experience with remote education on a scale of 1 to 10 , with 10 being the highest, the ratings were located in a range of 7.5 to 10 , with 8 being the most frequent, which reflects that it was a good experience. However, it required a significant effort, especially for professors without previous 
experience in remote education, also considering that there was a short time available to prepare the courses. Hence, when asked to describe their experience with a word, they mentioned wonderful, resilience, open minded, satisfaction, interesting, challenging, complex, contingency.

Finally, to improve remote education, the interviewed professors suggest:

- Standardize the educational platforms to be used and train teachers regarding activities that students can perform asynchronously.

- Promote self-taught learning among students and train them in the use of educational platforms, and in general in the use of information and communication technologies applied to the teaching-learning process.

- Use an educational platform of their own to facilitate access to students and make them feel part of the university.

- Give teachers courses on how to evaluate students in remote mode.

- Greater support for teachers with licenses, rubrics, teaching materials developed by specialists.

- Promote activities that avoid the dehumanization of the teaching-learning process.

\section{Conclusions}

The Emerging Remote Teaching Project fulfilled the objective of giving continuity to the academic activities of the institution studied, in the context of the pandemic, and avoiding infections. However, it represented an additional effort for professors, particularly for those who were not familiar with this modality, since they had to move from face-to-face to remote teaching in a short time.

The main challenges that teachers faced are related to the need to redesign / adapt their courses, generate didactic and evaluation strategies according to remote education, and learn or reinforce their knowledge regarding virtual classrooms and ICT applied to education.

On the other hand, they also had to overcome situations derived from inadequate conditions to carry out academic activities such as failures in the internet connection and lack of computer equipment on the part of the students and themselves; as well as teaching their classes in an environment of uncertainty, and in some cases, facing situations related to the contagion of Covid-19 from relatives, colleagues or close people.

In general terms, it was a process that demanded an open mind, a collaborative attitude and a high degree of resilience on the part of the teachers, as well as the students.

Regarding the institution, the lack of an adequate infrastructure to teach distant courses was revealed, so it would be advisable to standardize the use of virtual 
classrooms, create a bank of teaching materials and rubrics; as well as a continuing education program for professors and students, which remains after the contingency.

The pandemic came to make clear the need to incorporate new study modalities, which is why the institution is recommended to take advantage of the momentum, and to generate plans and study programs in hybrid or distance modality, as well as to move towards new forms of teaching and interaction between professors and students.

Regarding the research activities carried out by students, given that it is currently not feasible to go to organizations, it is recommended to establish agreements to interact remotely, as well as to carry out professional practices in the telework modality.

\section{References}

[1] Alfonso, I. (2003). La educación a distancia. ACIMED, 11(1), 3-4. http: //scielo.sld.cu/scielo.php?script=sciarttext\&pid=S1024-94352003000100 002003000100002\&Ing=es\&tlng=pt.

[2] Aparici, R. (2002). Mitos de la educación a distancia y de las nuevas tecnologías. Revista Iberoamericana de Educación a distancia, 5(1): 9-27.

[3] BBC (2020). Coronavirus: los gráficos que muestran cuáles son los focos de la pandemia en todo el mundo a 6 meses de su declaración. https://www. bbc.com/mundo/

[4] Dorrego, E. (2016). Educación a distancia y evaluación del aprendizaje. Revista de Educación a Distancia (RED), (50). https://revistas.um.es/red/article/view/271241

[5] Gobierno de México (2020). COVID 19 MÉXICO Información General. Nacional (Confirmados) 15 de septiembre 2020. https://coronavirus.gob.mx/datos/

[6] Navarro, J.C. (2020). Coronavirus. Mapa, muertes y casos de coronavirus en México por estado hoy 7 de octubre. mexico.as.com

[7] Padula, J. (2003). Una introducción a la educación a distancia. El ABC de la educación a distancia (conceptualizaciones). FCE. México. Pp. 1-9

[8] rtv.es (2020). Coronavirus. El mapa mundial del coronavirus: más de 36 millones de casos y más de un millón de

[9] Edutec. Revista Electrónica de Tecnología Educativa. 15. may 02: 1-8.

[10] UAM (2020). Proyecto Emergente de Enseñanza Remota. http://www.uam.mx/ educacionvirtual Muertos en todo el mundo. rtve.es

[11] Sánchez, M., Martínez, A. M., Torres, R., De Agüero, M., Hernández, A., Benavides, M., Rendón, V. y Jaimes, C. (2020). Retos educativos durante la pandemia de COVID-19: una encuesta a profesores de la UNAM. Vol. 21, 3, may-june 2020 Revista Digital Universitaria.

[12] Sangrà, A. (2002). Educación a distancia, educación presencial y usos de de la tecnología: una tríada para el progreso educativo. /uv/peer.html 